\title{
CAMA
}

Centre for Applied Macroeconomic Analysis

\section{The Political Consequences of Ethnic Tension: Theory and Evidence}

\section{CAMA Working Paper 72/2016 December 2016}

Kemal Kıvanç Aköz

New York University

K. Peren Arın

Zayed University and

Centre for Applied Macroeconomic Analysis, ANU

Christina Zenker

Zayed University

\section{Abstract}

By counting the number of articles published in major US newspapers containing carefully selected keywords, we construct a time varying measure of ethnic tension. Then, we empirically test the predictions of a theoretical model by using the aforementioned measure, and investigate how ethnic tension affects presidential approval ratings by different ethnic groups. Our results show that while ethnic tension decreases the approval by white voters, the opposite is true for the approval by African American voters. Further scrutiny reveals that this may be explained by the fact that government transfers to African Americans increase as a result of higher ethnic tension. 


\section{Keywords}

Ethnic Tension, Presidential Approval, Government Transfers

\section{JEL Classification}

J15, H11, H12, O15

Address for correspondence:

(E) cama.admin@anu.edu.au

\section{ISSN 2206-0332}

The Centre for Applied Macroeconomic Analysis in the Crawford School of Public Policy has been established to build strong links between professional macroeconomists. It provides a forum for quality macroeconomic research and discussion of policy issues between academia, government and the private sector.

The Crawford School of Public Policy is the Australian National University's public policy school, serving and influencing Australia, Asia and the Pacific through advanced policy research, graduate and executive education, and policy impact. 


\title{
The Political Consequences of Ethnic Tension: Theory and Evidence*
}

\author{
Kemal Kıvanç Aköz, K. Peren Arın†and Christina Zenker ${ }^{\ddagger}$
}

October 8, 2016

\begin{abstract}
By counting the number of articles published in major US newspapers containing carefully selected keywords, we construct a time varying measure of ethnic tension. Then, we empirically test the predictions of a theoretical model by using the aforementioned measure, and investigate how ethnic tension affects presidential approval ratings by different ethnic groups. Our results show that while ethnic tension decreases the approval by white voters, the opposite is true for the approval by African American voters. Further scrutiny reveals that this may be explained by the fact that government transfers to African Americans increase as a result of higher ethnic tension.
\end{abstract}

Keywords: Ethnic Tension, Presidential Approval, Government

Transfers

JEL Classification: J15, H11, H12, O15

\footnotetext{
*We would like to thank Andre Seidel, Nicola Spagnolo, Marcel Thum, and Caroline Williams for their valuable input.

¥Aköz (Corresponding author): New York University Abu Dhabi, PO Box 903 NYC, NY 10276 (e-mail: kka227@nyu.edu). Arın: Zayed University, Abu Dhabi, UAE, and Centre for Applied Macroeconomic Analysis (CAMA), Canberra, Australia (e-mail:Kerim.Arin@zu.ac.ae). Zenker: Zayed University, Abu Dhabi, UAE (email:Christina.Zenker@zu.ac.ae). The authors declare that they have no relevant or material financial interests that relate to the research described in the paper.
} 


\section{Introduction}

Every society faces scarce resources and members of the society have an incentive to maximize their share of those scare resources as well as to engage in rent seeking. Buchanan et al.(1980) argue that rent seeking can promote the formation of competing special interest groups. Landa (1994) states that since given ethnic characteristics can easily be observed, ethnic identity is a cost effective way to form those special interest groups. Therefore, it is not surprising that often these "clubs" or "special interest groups" are formed based on ethnic origin (Caselli and Coleman 2013). This can lead to both violent and non-violent conflict, which has repercussions on the political and economic development of a country. Montalvo and Reynal-Querol (2005) suggest that such formation has macro-economic effects; the rent-seeking behavior of an ethnically polarized society can lead to reduced investment, as well as an increase in public consumption. It has also been shown that ethnic heterogeneity leads to a decline in the production of public goods (see e.g. Alesina, Baqir, and Easterly 2000). Alesina et al. (2015) contend that economic inequality across ethnic groups is a negative correlate of economic development. Another strand of literature shows a large negative effect of ethnic fractionalization on the quality of institutions (Easterly and Levine, 1997; Keefer and Knack, 2002; and Easterly, Ritzen, and Woolcock, 2006).

To our knowledge, all previous studies use time-invariant variables, like ethnic fractionalization (Collier 2000, Posner 2004) and ethno-linguistic fractionalization (Easterly and Levine 1997) indices, as a proxy for ethnic conflict. However, as Caselli and Coleman (2013) argue, ethnic fractionalization does not always lead to ethnic conflict and ethnic conflict is not time invariant. One can also argue that there does not need to be violent conflict for ethnic fractionalization to have macroeconomic effects. Non-violent conflict (or, tension) can motivate economic agents to engage in rent-seeking behavior as well. Measuring non-violent conflict, however, is not easy.

Ethnic discrimination, exploitation, and conflict are frequently in the news, and pervasive throughout history (Caselli and Coleman, 2013). Taking this as a starting point, we construct a time variant ethnic tension index for the United States, by counting the number of articles published in major US newspapers extracted from Bloomberg and that contain some carefully chosen keywords. To our knowledge, we are the first to attempt to construct an index that includes a measure of both violent and non-violent conflict. We use this newly constructed index to investigate the political consequences of ethnic tension, more specifically on presidential approval ratings.

In this paper, we provide a theoretical framework that treats non-violent ethnic tension as a result of a political bargaining process. The government is under electoral pressure to push for redistribution policies that favor the ethnic majority. However, some governments have the flexibility to resist this pressure and pursue the alternative, more egalitarian redistribution policies. ${ }^{1}$ Ethnic minority members, then participate in the political bargaining process via non-electoral means to

\footnotetext{
${ }^{1}$ From the perspective of median-voter theorem, it makes sense that the elected officials choose policy platforms that favor ethnic majorities over the minorities. See Lewis (2013) for an empirical support for the claim that minority rights have lower priority in the electoral policy making process in the US.
} 
both counter-balance the electoral pressure and to learn if the government is indeed flexible to implement the alternative policies. Members of both the minority and majority groups then evaluates the government based on its response to ethnic tension. Employing our theoretical framework, we hypothesize that the assessment of government by minority and majority members measured by the presidential approval by White majority members and African American minority members in the US depends on ethnic tension. In particular, we argue that ethnic tension is positively associated with presidential approval by African American minority members and negatively associated with the presidential approval by White majority members.

Our results show that ethnic tension decreases presidential approval ratings by white voters, while it increases the approval ratings by African American voters. This might seem counterintuitive; however, closer scrutiny reveals that our results are not unfounded. We find that government transfers to African Americans increase as a result of ethnic tension.

The remainder of our paper is organized as follows: Section II provides a theoretical framework for our analysis. The data and methodology used are discussed in section III. Section IV presents the empirical results and section $\mathrm{V}$ concludes.

\section{The Theory}

\subsection{The Model}

Consider a static game with three players; "the president", "the minority" and "the majority". Let $J$ denote the majority and $N$ denote the minority. Assume that the minority and the majority can be publicly distinguishable. The minority has a lower weight in the population than the majority. Therefore, any executive, who has to win a majority voting competition to be appointed, in particular the president, would like to appeal to the majority. Therefore, whenever the president faces a decision regarding redistribution of resources between the minority and majority, the president will choose to maximize the returns to the majority and minimize the returns to the minority.

Suppose that the president has to redistribute a fixed and publicly known amount of resources $R$ between the minority and the majority. The default policy is to transfer $R_{0}$ to the minority, where

$$
0<R_{0}<R
$$

Typically, $R_{0}<1-R_{0}$, so that the total amount of resources devoted to the majority is higher than the resources devoted to the minority. However, this restriction on the redistribution is not necessary for our analysis. What is critical for our analysis is that the majority is able to hold the president accountable for her actions by means of elections, while the minority does not have that power against the president.

We assume that the minority has a costly action to force the president to make concessions to them by increasing the share that minority receives from the total resources, $R$. We call this costly 
action "raising tension", which we denote as $T$. The default action for the minority is to do nothing. ${ }^{2}$

The tension raised by the minority directly and adversely affects the well-being of the majority. The level of this effect depends on the response of the police force or the administration in general. If the administration responds by escalating the tension, "E", by means of excessive use of armed police and/or other means, the minority suffers from the conflict and receives a payoff of $R_{E}<R_{0}$. If the administration responds by "giving in", $G$, then the policy of redistribution changes and the minority receives $R_{G}>R_{0}$. If the administration does not respond to the tension $\varnothing$, the redistribution policy does not change and since there is no conflict between the minority and the administration, the minority is minimally affected. For simplicity assume that the payoff to minority in this case $R_{\varnothing}=R_{0}$.

The majority, on the other hand, receives $R-R_{0}$, when there is no tension in the society. However, the tension reduces the well-being of the majority no matter how the tension is resolved. For simplicity, assume that the payoff to the majority whenever there is tension is

$$
R-R_{G}<R-R_{0}
$$

Note that the payoff function for the majority as we described above implies that some of the resources are lost whenever there is tension and the administration does not contain the tension by giving concessions to the minority. Efficiency dictates that the president respond by giving in whenever the minority raises tension. However, reelection considerations might force the president to commit to the policy of escalation if it faces tension raised by the minority. For the benchmark model that we describe here, we abstract from the incentives for the president for commitment to escalation and instead assume that the response of the administration is partially determined by the "type" of president.

The president could support a tough policy against tensions because of her ideology, her connections to interest groups and bureaucratic institutions, and/or her political capital. Various factors determine the flexibility of the president towards giving concessions to the minority. In the discussions here, we do not specify president's preferences and constraints, and assume for simplicity that her type directly determines her action. In particular, the type space of the president is $\{E ; \varnothing ; G\}$.

Given the type of president, and so her action, the response of the administration is determined probabilistically. The president's action may be interpreted as a direct order by the senior executives; however, the exact implication of the order at the junior level may depend on many factors. We assume that the president's action increases the likelihood of the implementation of the same action by the administration but does not fully determine it.

Once the response of the administration is realized, the payoffs are realized as well and both the minority and majority update their belief about the type of the president. Based on the preferences of

\footnotetext{
${ }^{2}$ The costly action by the minority can be interpreted as the set of collective actions that the members of minority can take, such as demonstrations, protests, boycotting, riots.
} 
the minority and majority, each of the two groups' posterior belief that the president is of its favorite type will determine the group's approval of the president.

\subsubsection{Notation and Timeline}

First, the type of president is randomly picked from a prior distribution. For each type of president $i \in\{E ; \varnothing ; G\}$ let $\phi_{i}$ denote the prior probability that the president's type is $i$.

Given the type of president $i \in\{E ; \varnothing ; G\}$, the minority receives an informative signal $s_{N} \in\{E ; \varnothing ; G\}$ about the type of president. The signal being informative requires that the probability that the signal that the minority receives equals the actual type of president is higher than the signal equals another type. Equivalently,

$$
P\left(s_{N}=i \mid \tau=i\right)>\frac{1}{3},
$$

where $\tau$ denotes the type of president. To simplify the notation, assume that the probability that the signal is truthful is $\rho>1 / 3$ irrespective of the type of president, and the remaining two cases occur with equal probability of $(1-\rho) / 2$.

Given the signal $s_{N}$, the minority decides whether to raise tension or not based on the posterior expected payoff. The payoff of doing nothing is $R_{0}$ irrespective of the type of president. The payoff of raising tension is

$$
E\left(R_{N} \mid s\right)=\sum_{i \in\{E ; \varnothing ; G\}} R_{i} \sum_{\tau} P(\alpha=i \mid \tau) P(\tau \mid s),
$$

where $\alpha$ denotes the response of the administration, $R_{E}=0<R_{\varnothing}=R_{0}<R_{G}$ as specified above.

After the action of the minority, the administration's response is realized. As we discussed above, the administration's response is influenced by the president's action, but not fully determined by it. Let $\gamma$ be the probability that the administration's response is the same as the president's action. For simplicity, again we will assume that the probability of the remaining two cases occurring is an equal probability $(1-\gamma) / 2$.

\subsection{Raising Tension}

Given the notation above, we can start solving the decision problem of the minority by calculating the posterior probability distribution of the administration's response given the signal, $s$, that the minority receives. 


$$
P(\alpha \mid \tau) P(\tau \mid s)= \begin{cases}\frac{\gamma \rho \phi_{s}}{\rho \phi_{s}+\sum_{s^{\prime} \neq s} \frac{(1-\rho)}{2} \phi_{s}^{\prime}} & \text { if } s=\tau \& \alpha=\tau \\ \frac{\gamma \frac{(1-\rho)}{2} \phi_{\tau}}{\rho \phi_{s}+\frac{(1-\rho)}{2} \phi_{\tau}+\frac{(1-\rho)}{2} \phi_{\tau^{\prime}}} & \text { if } s \neq \tau \& \alpha=\tau \\ \frac{\frac{(1-\gamma)}{2} \rho \phi_{s}}{\rho \phi_{s}+\sum_{s^{\prime} \neq s} \frac{(1-\rho)}{2} \phi_{s}^{\prime}} & \text { if } s=\tau \& \alpha \neq \tau \\ \frac{\frac{(1-\gamma)}{2} \frac{(1-\rho)}{2} \phi_{\tau}}{\rho \phi_{s}+\frac{(1-\rho)}{2} \phi_{\tau}+\frac{(1-\rho)}{2} \phi_{\tau^{\prime}}} & \text { if } s \neq \tau \& \alpha \neq \tau .\end{cases}
$$

The minority weighs the payoff that it expects to receive by raising tension against the odds that the administration might response by escalating the tension. If the signal that the minority receives is interpreted as the president being more flexible in giving in, the minority will be more likely to raise tension since raising tension should lead to a higher expected payoff. The following Lemma states this.

Lemma 1 Assume that the priors are uniform; that is, $\phi_{E}=\phi_{\varnothing}=\phi_{G}=1 / 3$. Expected returns to the minority for raising tension is monotonic in signals; that is,

$$
\mathbb{E}\left(R_{N} \mid E\right)<\mathbb{E}\left(R_{N} \mid \varnothing\right)<\mathbb{E}\left(R_{N} \mid G\right) .
$$

Monotonicity of expected returns for raising tension forces the minority to act only if it receives a favorable signal about the president's type. Moreover, it is possible to argue that a necessary condition for the minority to rise tension is

$$
\mathbb{E}\left(R_{N} \mid G\right)>R_{0}
$$

so that raising tension is a better alternative then doing nothing and receiving $R_{0}$ as the certainty payoff. If the concession payoff $R_{G}$ is large enough, then the minority would always take the risk of escalation and raise tension. On the other hand, if $R_{G}$ is too low, then the minority would never raise tension. A more realistic scenario that will capture the variation in the tension level that we observe in the data would require that the minority would not raise tension after receiving the least favorable signal. To make things more concrete, we will concentrate on the cases where the minority raises tension only after receiving the most favorable signal $s=G$. The following proposition provides a necessary and sufficient condition for this scenario to hold.

Proposition 1 Assume that the priors are uniform; that is, $\phi_{E}=\phi_{\varnothing}=\phi_{G}=1 / 3$. The following inequalities are both necessary and sufficient for the minority to rise tension if and only if it receives $G$ as the signal on the president's type:

$$
\frac{3(1+\rho) R_{0}}{2}<R_{G}<\frac{7 R_{0}}{3}
$$


The main implication of Proposition 6 is that there is a wide range of payoffs that makes ethnic tension directly associated with the most favorable signal $s=G$. The minority rises tension if and only if it receives the signal $s=G$. Therefore, whenever the majority observes that there is tension, so its payoff reduces from $R-R_{0}$ to $R-R_{G}$, it can directly infer that the minority has received the signal $s=G$. Since this outcome is most likely when the president herself is of type $G$, the majority infers this as an information that president is not likely to be of the best type that the majority would prefer.

\subsection{Presidential Approval}

Given the framework we offer above, we can now interpret the presidential approval as the posterior belief that the president is of the most favorable type. For the minority, the payoff is highest when the president of type $G$. On the other hand, the majority prefer the president not to be of type $G$. Then the presidential approval rate by the minority could be calculated as the posterior probability that president is of type $G$. For the majority, it could be the posterior probability that president is not of type $G$.

Specifically, the presidential approval by the majority, when there is no tension

$$
\begin{gathered}
P(\tau \neq G \mid s \neq G)=P(\tau=E \mid s \neq G)+P(\tau=\varnothing \mid s \neq G) \\
=\frac{P(s \neq G \mid \tau=E) P(\tau=E)+P(s \neq G \mid \tau=\varnothing) P(\tau=\varnothing)}{\sum P(s \neq G \mid \tau) P(\tau)} \\
\frac{2 \frac{1+\rho}{2}}{2 \frac{1+\rho}{2}+1-\rho}=\frac{1+\rho}{2}
\end{gathered}
$$

and when there is tension

$$
P(\tau \neq G \mid s=G)=P(\tau=E \mid s=G)+P(\tau=\varnothing \mid s=G)=1-\rho .
$$

The presidential approval by the majority decreases by $\frac{3 \rho-1}{2}$ when there is tension. Symmetrically, the presidential approval by the minority increases by the same amount when there is tension. Following proposition states this finding.

Proposition 2 Assume that the priors are uniform; that is, $\phi_{E}=\phi_{\varnothing}=\phi_{G}=1 / 3$ and the payoffs satisfy the inequality (6). Then the presidential approval by the majority (minority) members is lower (higher) when there is ethnic tension by $\frac{3 \rho-1}{2}$.

\subsection{The Hypotheses}

Our theoretical framework provides an explanation for the relation between identity-based tension and approval for elected governments. In the context of US-politics, our theoretical framework 
argues for a significant relation between ethnic tension between Afro-Americans and White Americans and/or Afro-Americans and the administration, and the variation in Presidential Approval. In particular, we find analytically that ceteris paribus whenever there is ethnic tension, we can hypothesize that the members of the African American minority have the belief that the President likely has the flexibility to respond positively to the demands by the minority for more equitable redistribution. This directly implies that there should be a positive and significant correlation between ethnic tension and presidential approval by the African American voters.

The White majority, on the other hand, does not favor a president who has the flexibility for defending a more equitable redistribution policy, since such a policy would likely to reduce the wellbeing of them. The members of the White majority interpret ethnic tension as the president is likely to defend a policy that reduces their welfare. Therefore, whenever the members of White majority observe ethnic tension, they update their prior beliefs about the President to have a less favorable assessment of her. As a result, we should see a negative and significant correlation between the presidential approval by the White majority of voters and ethnic tension.

We can summarize our findings by the following two hypotheses:

Hypothesis 1 Even after we control for all other relevant variables, there is a positive and significant correlation between the Presidential Approval by the African American minority and an increase in ethnic tension in the US.

Hypothesis 2 Even after we control for all other relevant variables, there is a negative and significant correlation between the Presidential Approval by the White majority and an increase in ethnic tension in the US.

Since the White majority has more weight in the US population than the African American minority, when we aggregate the presidential approval by the two groups, we should find that the presidential approval by the White majority should dominate the population level approval rate.

Hypothesis 3 Even after we control for all other relevant variables, there is a negative and significant correlation between the Presidential Approval at the population level and an increase in ethnic tension in the US.

\subsubsection{Correlation vs. Causation}

There is an important caveat about our hypotheses. We do not argue that ethnic tension causes a particular direction of change in the presidential approval. Our theoretical framework concludes that a favorable information received by the African American minority about the hidden "type" of the president causes an increase in ethnic tension, which in turn causes a decrease in the presidential approval by the White majority of voters.

The available data, which we will discuss in the next section, does not allow us to directly measure the information that each ethnic group has about the president. Instead, what we can do is 
to see whether the correlations between the rates of presidential approval by specific ethnic groups and the ethnic tension that we can measure from our data confirm our theoretical hypotheses that we stated above even if we control for other relevant determinants of the presidential approval rates. As we will discuss clearly below, our empirical analysis detects a pattern of robust correlations that confirm our hypotheses.

\section{Data and Methodology}

Our dependent variable is the Presidential Approval ratings by Gallup ${ }^{3}$. Every month, Gallup surveys US voters on whether they approve or disapprove of the president. Specifically, people are asked: "Do you approve or disapprove of the way [Barack Obama] is handling his job as President?". Approval rates are available by gender, age, race, ideology, party affiliation, region, education and income level. We were able to retrieve the data from 1989 to 2015, and thus have data for the four most recent presidents: George H.W. Bush, Bill Clinton, George W. Bush and Barack Obama.

Our main variable of interest, the ethnic tension index is constructed by counting the number of articles that contain carefully selected keywords published in major US newspapers between 1989 and 2015. ${ }^{4}$ We constructed a benchmark index, which counts the articles including the terms "African American" and "Hispanic" as well as keywords with negative connotations 5 ("Negative" in the graph below). We also have an alternative index which counts only the two major words "African American" and "Hispanic" ("Neutral" in the graph below). The alternative index assumes that, in an ideal World, the race/ethnicity should not matter, and should not even be mentioned. See the below figure for a visual display of the data, which includes an explanation of the spikes in ethnic tension.

The unemployment rate statistics and Consumer Price Index statistics ( which were used to calculate monthly inflation rates) were downloaded from FRED. In line with Burden and Mughan (2003), Smyth et al. (1994), Chappell and Keech (1985), we added a variable called Honeymoon effect. This effect is based on the idea that when a president first takes office, the public and media tend to give the president the benefit of the doubt and treat him well. We used a 12-month decaying honeymoon variable, i.e. the honeymoon effect in the first month of the presidency is 12 , the second month 11 , etc.

To investigate the effects of ethnic tension on presidential approval ratings, we use regular regression analysis and estimate the following model:

$\mathrm{PA}(\mathrm{T})=a_{0}+a_{1}$ UNEMPLOYMENT $+a_{2}$ INFLATION $+a_{3}$ HONEYMOON

$+a_{4}$ REPUBLICAN $+a_{5}$ TENSION $+a_{6}$ TENSION*REPUBLICAN $+\varepsilon_{i}$

The above specifications closely follows Berlemann et al. (2014). We should note that errors are White (1980) corrected in our estimations.

\footnotetext{
${ }^{3}$ http://www.gallup.com/poll/124922/presidential-job-approval-center.aspx

${ }^{4}$ The search was conducted on a Bloomberg terminal, choosing âĂIJBloomberg and editorially suggested sourcesâĂI as source.

${ }^{5}$ Discrimination, crime, protest, fraud, violence, conflict, tension, illegal
} 
Figure 1: Ethnic Tension in the US

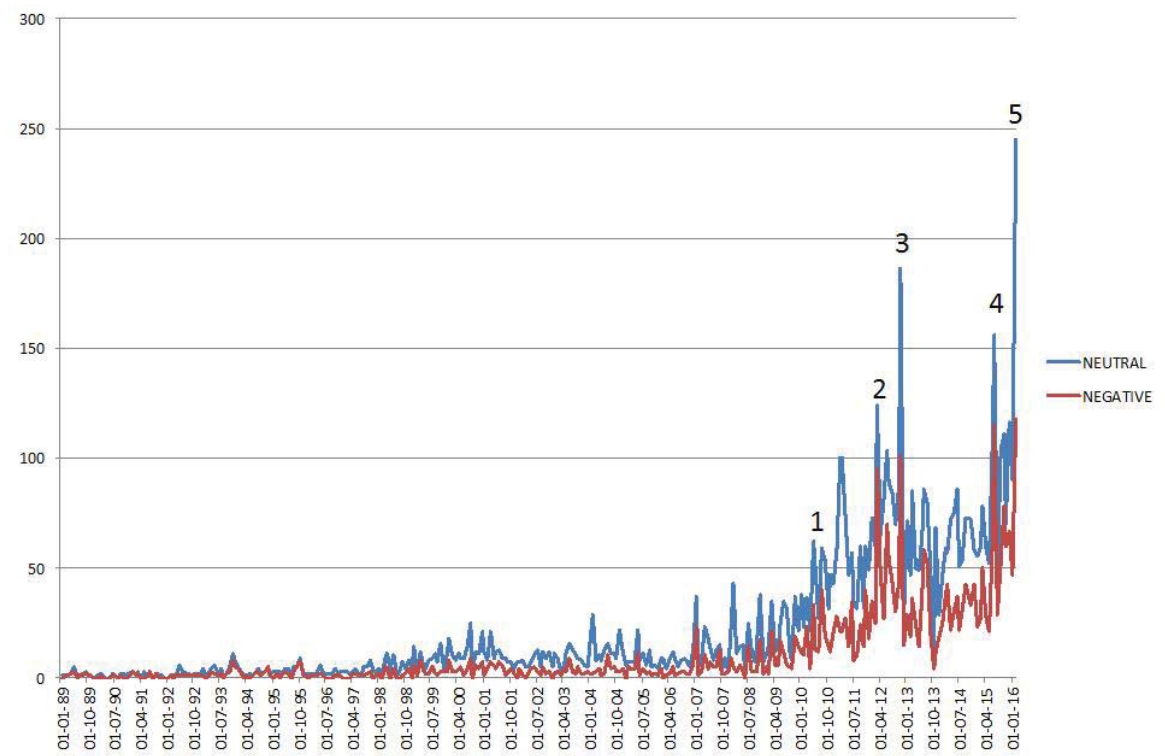

1: African American slain in Virginia

2: Trayvon Martin shooting

3: Presidential Election, Obama wins second term

4: Aftermath of Charleston shooting in black church in South Carolina; anniversary of Ferguson shooting

5: Racial conflicts surrounding Trump campaign

[TABLE 1 HERE]

\section{Empirical Analysis}

\subsection{The Benchmark Model}

The empirical results of our benchmark model are presented in Table 2. Consistent with Berlemann et al. (2014) we show that the unemployment rate has a negative and significant effect on approval rates while the honeymoon variable has a positive and significant effect (Regressions 1-4). Our results show that ethnic tension has a negative and significant effect on total approval rate, which confirms our theoretical hypothesis 3 . The ethnic tension has a negative and significant effect on approval rate by the White voters as well(Regressions 1 and 2), which confirms Hypothesis 2. On the other hand, it has a positive and significant effect on the approval rates by the African American voters (regression 3), which confirms Hypothesis 1.

These results confirm our theoretical approach that ethnic tension signals everyone that the Pres- 
ident is not willing to act aggressively against ethnic tension about redistribution. Then whenever there is ethnic tension in the society, the White voters fears that the President will work to change the redistribution in favor of the Afro-American minority. This inference reduces the approval of the President among the White majority. However, the same observation of ethnic tension by AfroAmerican minority leads to optimism about a favorable redistribution among the Afro-American minority, which increases the approval of the President by this group.

We also find that tension has no significant effect on the approval rate of other minorities (Regression 4). We should also note that the decrease in approval ratings is even larger for Republican presidents as a result of increased ethnic tension.

[TABLE 2 HERE]

\subsection{Robustness Checks}

In our first robustness check, we use an alternative tension index. Our results remain essentially the same when the ethnic tension index we used in our benchmark model is replaced with the alternative ethnic tension index. An interesting observation is that while the magnitude of the negative effect on approval rates by the white majority and the total approval rate are larger, the magnitude of the positive effect on African American minority is smaller.

\section{[TABLE 3 HERE]}

In our final robustness check, we replaced our major macroeconomic variables with their lagged values. The results are essentially the same with our previous results, and they are presented in Table 4:

\section{[TABLE 4 HERE]}

\subsection{Further Analysis: Why does Ethnic Tension Increase the Approval rat- ings of Minority Voters?}

Our main result, which shows that ethnic tension increases the approval ratings by African American voters, may seem counter-intuitive. Therefore, we conducted further analysis to see if the government reacts to ethnic tension by increasing transfers to minorities as a means to calming down violent and non-violent ethnic tension. To do so, we ran an additional regression, with log of transfers ${ }^{6}$ as the dependent and ethnic tension as the independent variable.

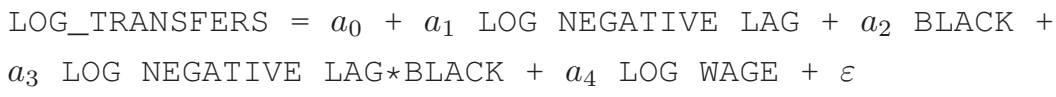

${ }^{6}$ We used the "Current Population Survey" brought together by Flood et al.(2015) for the data. 


\section{[TABLE 5 HERE]}

The empirical literature on political participation (Verba and Nie, 1987) suggests that, after controlling for socioeconomics status, African Americans have a higher propensity to participate in groups and to vote than whites. Hence it is not surprising that the government would increase transfers to African Americans to assuage them during ethnic tension.

\section{Conclusion}

The economics literature has documented that ethnic fractionalization has many adverse effects on major macroeconomic variables, assuming that ethnic fractionalization as a time-invariant concept can capture the magnitude of violent and non-violent conflict created by ethnic diversity. In this paper, we argued that this may not be the case: as not every ethnically fractionalized society faces ethnic conflict, and as ethnic conflict (especially non-violent ethnic conflict) can vary over time, using a time-invariant measure, like ethnic fractionalization may conceal the true effects of ethnic tension. To solve this potential bias, we propose a novel index, following the footsteps of Bloom (2009) by counting the number of articles published in major US media outlets that contain certain keywords. This novel index allows us to investigate the effects of ethnic tension on political variables, like presidential approval ratings that vary substantially over time. Our results from both a theoretical model, and basic regressions show that while the majority voters are unhappy with ethnic tension, certain minority groups see it as an opportunity to increase their share of scarce resources (possibly through governmental transfers). Needless to say, this particular result motivates further avenues of research, including the effects of non-violent ethnic tension on other major macroeconomic variables like consumption, investment, as well as the public provision of goods. 


\section{Appendix A - Proofs}

Proof of Lemma 1 The expected payoff to the minority for raising tension given the signal $s$ equals

$E$ is as follows:

$$
\begin{aligned}
& \mathbb{E}\left(R_{N} \mid E\right)= \\
& R_{E}\left(\frac{\gamma \rho \phi_{E}+\frac{(1-\gamma)}{2} \frac{(1-\rho)}{2} \phi_{\varnothing}+\frac{(1-\gamma)}{2} \frac{(1-\rho)}{2} \phi_{G}}{\rho \phi_{E}+\sum_{s^{\prime} \neq E} \frac{(1-\rho)}{2} \phi_{s}^{\prime}}\right) \\
+ & R_{0}\left(\frac{\left.\frac{(1-\gamma)}{2} \rho \phi_{E}+\gamma \frac{(1-\rho)}{2} \phi_{\varnothing}+\frac{(1-\gamma)}{2} \frac{(1-\rho)}{2} \phi_{G}\right)}{\rho \phi_{E}+\sum_{s^{\prime} \neq E} \frac{(1-\rho)}{2} \phi_{s}^{\prime}}\right) \\
+ & R_{G}\left(\frac{\left.\frac{(1-\gamma)}{2} \rho \phi_{E}+\frac{(1-\gamma)}{2} \frac{(1-\rho)}{2} \phi_{\varnothing}+\gamma \frac{(1-\rho)}{2} \phi_{G}\right)}{\rho \phi_{E}+\sum_{s^{\prime} \neq E} \frac{(1-\rho)}{2} \phi_{s}^{\prime}}\right)
\end{aligned}
$$

Similarly

$$
\begin{aligned}
& \mathbb{E}\left(R_{N} \mid \varnothing\right)= \\
& R_{E}\left(\frac{\gamma \frac{(1-\rho)}{2} \phi_{E}+\frac{(1-\gamma)}{2} \rho \phi_{\varnothing}+\frac{(1-\gamma)}{2} \frac{(1-\rho)}{2} \phi_{G}}{\rho \phi_{\varnothing}+\sum_{s^{\prime} \neq \varnothing} \frac{(1-\rho)}{2} \phi_{s}^{\prime}}\right) \\
+ & R_{0}\left(\frac{\left.\frac{(1-\gamma)}{2} \frac{(1-\rho)}{2} \phi_{E}+\gamma \rho \phi_{\varnothing}+\frac{(1-\gamma)}{2} \frac{(1-\rho)}{2} \phi_{G}\right)}{\rho \phi_{\varnothing}+\sum_{s^{\prime} \neq \varnothing} \frac{(1-\rho)}{2} \phi_{s}^{\prime}}\right) \\
+ & R_{G}\left(\frac{\left.\frac{(1-\gamma)}{2} \frac{(1-\rho)}{2} \phi_{E}+\frac{(1-\gamma)}{2} \rho \phi_{\varnothing}+\gamma \frac{(1-\rho)}{2} \phi_{G}\right)}{\rho \phi_{\varnothing}+\sum_{s^{\prime} \neq \varnothing} \frac{(1-\rho)}{2} \phi_{s}^{\prime}}\right)
\end{aligned}
$$

and

$$
\begin{aligned}
& \mathbb{E}\left(R_{N} \mid G\right)= \\
& R_{E}\left(\frac{\gamma \frac{(1-\rho)}{2} \phi_{E}+\frac{(1-\gamma)}{2} \frac{(1-\rho)}{2} \phi_{\varnothing}+\frac{(1-\gamma)}{2} \rho \phi_{G}}{\rho \phi_{G}+\sum_{s^{\prime} \neq G} \frac{(1-\rho)}{2} \phi_{s}^{\prime}}\right) \\
+ & R_{0}\left(\frac{\left.\frac{(1-\gamma)}{2} \frac{(1-\rho)}{2} \phi_{E}+\gamma \frac{(1-\rho)}{2} \phi_{\varnothing}+\frac{(1-\gamma)}{2} \rho \phi_{G}\right)}{\rho \phi_{G}+\sum_{s^{\prime} \neq G} \frac{(1-\rho)}{2} \phi_{s}^{\prime}}\right) \\
+ & R_{G}\left(\frac{\left.\frac{(1-\gamma)}{2} \frac{(1-\rho)}{2} \phi_{E}+\frac{(1-\gamma)}{2} \frac{(1-\rho)}{2} \phi_{\varnothing}+\gamma \rho \phi_{G}\right)}{\rho \phi_{G}+\sum_{s^{\prime} \neq G} \frac{(1-\rho)}{2} \phi_{s}^{\prime}}\right)
\end{aligned}
$$

Assuming uniform priors substantially simplify the expressions for expected returns. Below we check two inequalities to prove monotonicity. 


$$
\begin{gathered}
\mathbb{E}\left(R_{N} \mid E\right)<\mathbb{E}\left(R_{N} \mid \varnothing\right) \Leftrightarrow \\
R_{0}\left(\frac{(1-\gamma)}{2} \rho+\gamma \frac{(1-\rho)}{2}+\frac{(1-\gamma)}{2} \frac{(1-\rho)}{2}\right) \\
+R_{G}\left(\frac{(1-\gamma)}{2} \rho+\frac{(1-\gamma)}{2} \frac{(1-\rho)}{2}+\gamma \frac{(1-\rho)}{2}\right)> \\
R_{0}\left(\frac{(1-\gamma)}{2} \frac{(1-\rho)}{2}+\gamma \rho+\frac{(1-\gamma)}{2} \frac{(1-\rho)}{2}\right) \\
+R_{G}\left(\frac{(1-\gamma)}{2} \frac{(1-\rho)}{2}+\frac{(1-\gamma)}{2} \rho+\gamma \frac{(1-\rho)}{2}\right) \Leftrightarrow \\
\gamma \rho+\frac{(1-\gamma)}{2} \frac{(1-\rho)}{2}>\frac{(1-\gamma)}{2} \rho+\gamma \frac{(1-\rho)}{2} \Leftrightarrow \\
(1-3 \rho)(1-3 \gamma)>0,
\end{gathered}
$$

which is true since the signal $s$ that minority receives is informative; that is, $\rho>1 / 3$ and the president's type has an effect on administration's response; that is, $\gamma>1 / 3$. A similar argument shows

$$
\begin{gathered}
\mathbb{E}\left(R_{N} \mid \varnothing\right)<\mathbb{E}\left(R_{N} \mid G\right) \Leftrightarrow \\
(1-3 \rho)(1-3 \gamma)>0 .
\end{gathered}
$$

This completes the proof.

Proof of Proposition 1 By Lemma 1, it is sufficient to characterize the following inequality

$$
\mathbb{E}\left(R_{N} \mid \varnothing\right)<R_{0}<\mathbb{E}\left(R_{N} \mid G\right) .
$$

Now,

$$
\begin{gathered}
\mathbb{E}\left(R_{N} \mid \varnothing\right)<R_{0} \Leftrightarrow \\
R_{0}\left(\frac{(1-\gamma)(1-\rho)}{2}+\gamma \rho\right) \\
+R_{G}\left(\frac{(1-\gamma)(1-\rho)}{4}+\frac{(1-\gamma) \rho}{2}+\frac{\gamma(1-\rho)}{2}\right)<R_{0} \Leftrightarrow \\
R_{G}(1+\rho+\gamma-3 \gamma \rho)<R_{0}(2+2 \gamma+2 \rho-2 \gamma \rho) .
\end{gathered}
$$

Note that the coefficient in front of $R_{G}$ is decreasing in both $\gamma$ and $\rho$ and the coefficient in front of $R_{0}$ is increasing in both $\gamma$ and $\rho$. Therefore, the condition above holds for any $\gamma$ and $\rho$ if it holds 
for $\gamma, \rho=1 / 3$. Then

$$
\begin{gathered}
\mathbb{E}\left(R_{N} \mid \varnothing\right)<R_{0} \Leftrightarrow \\
R_{G} \frac{4}{3}<R_{0} \frac{28}{9} \Leftrightarrow \\
R_{G}<\frac{7}{3} R_{0} . \\
\mathbb{E}\left(R_{N} \mid G\right)>R_{0} \Leftrightarrow \\
R_{0}\left(\frac{(1-\gamma)(1-\rho)}{2}+\frac{\gamma(1-\rho)}{2}\right)+R_{G}\left(\frac{(1-\gamma)(1-\rho)}{2}+\gamma \rho\right)>R_{0} \Leftrightarrow \\
R_{G}(1-\gamma-\rho+3 \gamma \rho)>R_{0}(1+\rho) .
\end{gathered}
$$

Note that the coefficient in front of $R_{G}$ is increasing in $\gamma$, is the condition holds for $\gamma=1 / 3$, it will hold for any $\gamma$. Then

$$
\begin{aligned}
& \mathbb{E}\left(R_{N} \mid G\right)>R_{0} \Leftrightarrow \\
& R_{G}>\frac{3(1+\rho) R_{0}}{2},
\end{aligned}
$$

as required. 


\section{Appendix B - Tables}

Table 1: Description of the Variables

\begin{tabular}{|c|c|c|}
\hline Variable & Definition & Source \\
\hline Tension & $\begin{array}{l}\text { Index constructed with counts of carefully } \\
\text { selected keywords from major US media } \\
\text { outlets, including keywords with negative } \\
\text { connotation such as "crime". }\end{array}$ & Bloomberg \\
\hline Alt-Tension & $\begin{array}{l}\text { Index constructed with counts of carefully } \\
\text { selected keywords with neutral connota- } \\
\text { tions from major US media outlets. }\end{array}$ & Bloomberg \\
\hline Total Approval & $\begin{array}{l}\text { Percentage of surveyed US voters approv- } \\
\text { ing of the way the incumbent president } \\
\text { handles his job. }\end{array}$ & Gallup \\
\hline White & $\begin{array}{l}\text { Percentage of surveyed white US voters } \\
\text { approving of the way the incumbent pres- } \\
\text { ident handles his job. }\end{array}$ & Gallup \\
\hline African American & $\begin{array}{l}\text { Percentage of surveyed African American } \\
\text { voters approving of the way the incumbent } \\
\text { president handles his job. }\end{array}$ & Gallup \\
\hline Non-White & $\begin{array}{l}\text { Percentage of surveyed US voters who are } \\
\text { neither white nor African American, ap- } \\
\text { proving of the way the incumbent presi- } \\
\text { dent handles his job. }\end{array}$ & Gallup \\
\hline Unemp. rate & Monthly US unemployment rate & FRED \\
\hline Inflation & Monthly US inflation rate & FRED \\
\hline Honeymoon & $\begin{array}{l}\text { Variable measuring the effect of "warm } \\
\text { glow" in the early months of a president's } \\
\text { incumbency }\end{array}$ & Self-constructed \\
\hline Republican & $\begin{array}{l}\text { Dummy variable which takes on value of } 1 \\
\text { when incumbent president is Republican. }\end{array}$ & Self-constructed \\
\hline Wage & Yearly pre-tax and salary income. & IPUMS-CPS database \\
\hline Black & $\begin{array}{l}\text { Dummy variable which takes on value of } \\
1 \text { when the person is black. }\end{array}$ & IPUMS-CPS database \\
\hline
\end{tabular}


Table 2: Regression Results - Benchmark Model

\begin{tabular}{|c|c|c|c|c|}
\hline & $\begin{array}{c}\text { (1) } \\
\text { Total Approval }\end{array}$ & $\begin{array}{c}(2) \\
\text { White }\end{array}$ & $\begin{array}{c}\text { (3) } \\
\text { African American }\end{array}$ & $\begin{array}{c}(4) \\
\text { Non-White }\end{array}$ \\
\hline Unemployment Rate & $\begin{array}{c}-1.487^{* * *} \\
(-3.93)\end{array}$ & $\begin{array}{c}-1.585^{* * *} \\
(-3.94)\end{array}$ & $\begin{array}{c}-0.665^{*} \\
(-1.79)\end{array}$ & $\begin{array}{c}-1.711^{* * *} \\
(-4.32)\end{array}$ \\
\hline Inflation & $\begin{array}{l}-0.340 \\
(-0.11)\end{array}$ & $\begin{array}{l}0.307 \\
(0.10)\end{array}$ & $\begin{array}{l}-0.334 \\
(-0.11)\end{array}$ & $\begin{array}{l}-0.963 \\
(-0.32)\end{array}$ \\
\hline Honeymoon & $\begin{array}{c}0.852^{* * *} \\
(4.18)\end{array}$ & $\begin{array}{c}0.782^{* * *} \\
(3.71)\end{array}$ & $\begin{array}{c}0.858^{* * *} \\
(4.04)\end{array}$ & $\begin{array}{c}0.592^{* * *} \\
(3.10)\end{array}$ \\
\hline Republican & $\begin{array}{c}10.817^{* * *} \\
(3.88)\end{array}$ & $\begin{array}{c}13.928^{* * *} \\
(4.67)\end{array}$ & $\begin{array}{c}-28.067^{* * *} \\
(-8.69)\end{array}$ & $\begin{array}{c}-17.172^{* * *} \\
(-5.23)\end{array}$ \\
\hline Tension & $\begin{array}{c}-1.023^{* *} \\
(-2.09)\end{array}$ & $\begin{array}{c}-3.016^{* * *} \\
(-5.54)\end{array}$ & $\begin{array}{c}3.456^{* * *} \\
(7.60)\end{array}$ & $\begin{array}{l}0.113 \\
(0.23)\end{array}$ \\
\hline Tension* Rep. & $\begin{array}{c}-6.188^{* * *} \\
(-4.96)\end{array}$ & $\begin{array}{c}-3.341^{* *} \\
(-2.49)\end{array}$ & $\begin{array}{c}-14.178^{* * *} \\
(-11.00)\end{array}$ & $\begin{array}{c}-10.225^{* * *} \\
(-7.52)\end{array}$ \\
\hline Constant & $\begin{array}{c}63.724^{* * *} \\
(31.83)\end{array}$ & $\begin{array}{c}63.311^{* * *} \\
(29.57)\end{array}$ & $\begin{array}{c}79.064^{* * *} \\
(36.89)\end{array}$ & $\begin{array}{c}84.145^{* * *} \\
40.02)\end{array}$ \\
\hline $\mathrm{N}$ & 317 & 312 & 305 & 312 \\
\hline$R^{2}$ & 0.191 & 0.354 & 0.875 & 0.721 \\
\hline $\mathrm{F}$ & 23.856 & 57.791 & 363.233 & 134.783 \\
\hline
\end{tabular}


Table 3: Regression Results - Robustness Check

\begin{tabular}{|c|c|c|c|c|}
\hline & $\begin{array}{c}\text { (1) } \\
\text { Total Approval }\end{array}$ & $\begin{array}{c}(2) \\
\text { White }\end{array}$ & $\begin{array}{c}\text { (3) } \\
\text { African American }\end{array}$ & $\begin{array}{c}\text { (4) } \\
\text { Non-White }\end{array}$ \\
\hline Unemp. Rate & $\begin{array}{c}-1.145^{* * *} \\
(-2.95)\end{array}$ & $\begin{array}{c}-1.289^{* * *} \\
(-3.18)\end{array}$ & $\begin{array}{l}-0.077 \\
(-0.19)\end{array}$ & $\begin{array}{c}-1.324^{* * *} \\
(-3.13)\end{array}$ \\
\hline Inflation & $\begin{array}{l}-0.233 \\
(-0.08)\end{array}$ & $\begin{array}{l}0.371 \\
(0.12)\end{array}$ & $\begin{array}{l}0.216 \\
(0.07)\end{array}$ & $\begin{array}{l}-0.462 \\
(-0.15)\end{array}$ \\
\hline Honeymoon & $\begin{array}{c}0.885^{* * *} \\
(4.48)\end{array}$ & $\begin{array}{c}0.809^{* * *} \\
(4.08)\end{array}$ & $\begin{array}{c}0.815^{* * *} \\
(3.36)\end{array}$ & $\begin{array}{c}0.638^{* * *} \\
(3.16)\end{array}$ \\
\hline Republican & $\begin{array}{c}5.598^{* *} \\
(2.32)\end{array}$ & $\begin{array}{c}10.551^{* * *} \\
(4.24)\end{array}$ & $\begin{array}{c}-41.480^{* * *} \\
(-13.77)\end{array}$ & $\begin{array}{c}-25.840^{* * *} \\
(-9.21)\end{array}$ \\
\hline Alt. Tension & $\begin{array}{c}-1.702^{* * *} \\
(-3.58)\end{array}$ & $\begin{array}{c}-3.670^{* * *} \\
(-7.12)\end{array}$ & $\begin{array}{c}2.569^{* * *} \\
(5.18)\end{array}$ & $\begin{array}{l}-0.430 \\
(-0.83)\end{array}$ \\
\hline Alt Tens. * Repub & $\begin{array}{c}-5.912^{* * *} \\
(-3.54)\end{array}$ & $\begin{array}{c}-2.962^{*} \\
(-1.72)\end{array}$ & $\begin{array}{c}-12.281^{* * *} \\
(-6.53)\end{array}$ & $\begin{array}{c}-9.579^{* * *} \\
(-5.28)\end{array}$ \\
\hline Constant & $\begin{array}{c}62.019^{* * *} \\
(28.75)\end{array}$ & $\begin{array}{c}60.432^{* * *} \\
(26.74)\end{array}$ & $\begin{array}{c}79.377^{* * *} \\
(33.81)\end{array}$ & $\begin{array}{c}82.628^{* * *} \\
(35.48)\end{array}$ \\
\hline $\mathrm{N}$ & 317 & 312 & 305 & 312 \\
\hline$R^{2}$ & 0.167 & 0.347 & 0.858 & 0.697 \\
\hline $\mathrm{F}$ & 21.666 & 59.856 & 317.979 & 114.866 \\
\hline
\end{tabular}


Table 4: Regression Results - Robustness Check 2

\begin{tabular}{lcccc}
\hline \multicolumn{5}{c}{ Table 4: Regression Results - Robustness Check 2} \\
& Total Approval & White & African American & Non-White \\
\hline Lagged Un. Rate & $-1.328^{* * *}$ & $-1.472^{* * *}$ & -0.194 & $-1.514^{* * *}$ \\
& $(-3.30)$ & $(-3.52)$ & $(-0.47)$ & $(-3.49)$ \\
Lagged Inflation & -1.970 & -1.912 & -1.064 & -2.265 \\
& $(-0.66)$ & $(-0.64)$ & $(-0.34)$ & $(-0.74)$ \\
Honeymoon & $0.931^{* * *}$ & $0.865^{* * *}$ & $0.792^{* * *}$ & $0.667^{* * *}$ \\
& $(4.80)$ & $(4.49)$ & $(3.19)$ & $(3.31)$ \\
Republican & $6.114^{* *}$ & $11.187^{* * *}$ & $-41.409^{* * *}$ & $-25.423^{* * *}$ \\
& $(2.50)$ & $(4.46)$ & $(-13.48)$ & $(-8.84)$ \\
Tension & $-1.587^{* * *}$ & $-3.562^{* * *}$ & $2.621^{* * *}$ & -0.319 \\
& $(-3.26)$ & $(-6.74)$ & $(5.11)$ & $(-0.60)$ \\
Tension * Repub. & $-6.358^{* * *}$ & $-3.490^{*}$ & $-12.375^{* * *}$ & $-9.975^{* * *}$ \\
& $(-3.68)$ & $(-1.96)$ & $(-6.35)$ & $(-5.29)$ \\
Constant & $63.295^{* * *}$ & $61.823^{* * *}$ & $80.293^{* * *}$ & $83.997^{* * *}$ \\
& $(27.99)$ & $(26.16)$ & $(33.05)$ & $(34.52)$ \\
\hline $\mathrm{N}$ & 316 & 311 & 304 & 311 \\
$R^{2}$ & 0.172 & 0.351 & 0.858 & 0.700 \\
$\mathrm{~F}$ & 21.797 & 59.565 & 309.092 & 113.211 \\
\hline$t$ statistics in parenthe
\end{tabular}

statistics in parentheses

${ }^{*} \mathrm{p}<0.10,{ }^{* *} \mathrm{p}<0.05,{ }^{* * *} \mathrm{p}<0.01$ 
Table 5: Transfers

Dependent variable: Log transfers

\begin{tabular}{|c|c|c|c|c|}
\hline & (1) & (2) & (3) & (4) \\
\hline LOG NEG & $\begin{array}{c}0.0455^{* * *} \\
(80.36)\end{array}$ & $\begin{array}{c}0.0580^{* * *} \\
(38.70)\end{array}$ & $\begin{array}{l}\cdots \\
\ldots\end{array}$ & $\begin{array}{l}\cdots \\
\ldots\end{array}$ \\
\hline BLACK & $\begin{array}{c}-0.218^{* * *} \\
(-44.44)\end{array}$ & $\begin{array}{c}-0.210^{* * *} \\
(-43.35)\end{array}$ & $\begin{array}{c}-0.219^{* * *} \\
(-44.40)\end{array}$ & $\begin{array}{c}-0.210^{* * *} \\
(-43.35)\end{array}$ \\
\hline LOG NEG * BLACK & $\begin{array}{c}0.025^{* * *} \\
(11.91)\end{array}$ & $\begin{array}{c}0.0230^{* * *} \\
(11.22)\end{array}$ & $\begin{array}{l}\ldots \\
\ldots\end{array}$ & $\begin{array}{l}\ldots \\
\ldots\end{array}$ \\
\hline LOG WAGE & $\ldots$ & $\begin{array}{c}0.393^{* * *} \\
(57.86)\end{array}$ & $\ldots$ & $\begin{array}{c}0.393^{* * *} \\
(57.86)\end{array}$ \\
\hline LOG NEG LAG & $\begin{array}{l}\ldots \\
\cdots\end{array}$ & $\ldots$ & $\begin{array}{c}0.045^{* * *} \\
(80.36)\end{array}$ & $\begin{array}{c}-0.116^{*} \\
(-1.92)\end{array}$ \\
\hline LOG NEG LAG * BLACK & $\begin{array}{l}\ldots \\
\ldots\end{array}$ & $\begin{array}{l}\ldots \\
\ldots\end{array}$ & $\begin{array}{c}0.025^{* * *} \\
(11.91)\end{array}$ & $\begin{array}{c}0.023^{* * *} \\
(11.22)\end{array}$ \\
\hline $\begin{array}{l}\text { Constant } \\
(8033.60)\end{array}$ & $\begin{array}{l}11.25^{* * *} \\
(297.11)\end{array}$ & $\begin{array}{c}9.391^{* * *} \\
(8033.61)\end{array}$ & $\begin{array}{c}11.246^{* * *} \\
(297.11)\end{array}$ & $9.391^{* * *}$ \\
\hline $\mathrm{N}$ & $1,416,173$ & $1,415,768$ & $1,416,173$ & $1,415,768$ \\
\hline$R^{2}$ & 0.0094 & 0.030 & 0.0094 & 0.030 \\
\hline $\mathrm{F}$ & 3866.55 & 770.11 & 3866.54 & 743.61 \\
\hline
\end{tabular}




\section{References}

Alesina, Alberto, Reza Baqir, and William Easterly. 2000. "Redistributive Public Employment." Journal of Urban Economics 48 (2): 219-241.

Alesina, Alberto, Stelios Michalopoulos, and Elias Papaioannou. 2015. "Ethnic Inequality." Journal of Political Economy 123 (3): 547-724.

Berlemann, Michael, and Sören Enkelmann. 2014. "The Economic Determinants of US Presidential Approval: A Survey." European Journal of Political Economy 36:41-54.

Bloom, Nicholas. 2009. "The Impact of Unceainty Shocks.” Econometrica 77 (3): 623-685.

Buchanan, James M., Robert D. Tollison, and Gordon Tullock (eds). 1980. Toward a Theory of the Rent-Seeking Society. Texas A\&M University Press.

Burden, Barry C., and Anthony Mughan. 2003. "The International Economy and Presidential Approval.” Public Opinion Quarterly 67 (4): 555-578.

Caselli, Francesco, and Wilbur John Coleman. 2013. "On the Theory of Ethnic Conflict.” Journal of European Economic Association 11 (1): 161-192.

Chappell, Henry W., and William R. Keech. 2013. "A New View of Political Accountability for Economic Performance.” American Political Science Review 79 (1): 10-27.

Collier, Paul. 2000. Economic Causes of Civil Conflict and Their Cmplications for Policy. Washington DC: World Bank.

Easterly, William, and Ross Levine. 1997. “Africa's Growth Tragedy: Policies and Ethnic Divisions." The Quarterly Journal of Economics 112 (4): 1203-1250.

Easterly, William, Jozef Ritzen, and Michael Woolcock. 2006. "Social cohesion, institutions, and growth." Economics\&Politics 18 (2): 103-120.

Flood, Sarah, Miriam King, Steven Ruggles, and J. Robert Warren. 2015. Integrated Public Use Microdata Series, Current Population Survey: Version 4.0 [Machine-readable database]. Minneapolis: University of Minnesota.

Gallup. Presidential Job Approval Center. http://www.gallup.com/poll/124922/ presidential-job-approval-center. aspx. Accessed: June-2016.

Keefer, Philip, and Stephen Knack. 2002. "Polarization, Politics and Property Rights: Links between Inequality and Growth." Public Choice 111 (1-2): 127-154.

Landa, Janet T. 1994. Trust, Ethnicity, and Identity: Beyond the New Institutional Economics of Ethnic Trading Networks, Contract Law, and Gift-exchange. Ann Arbor: University of Michigan Press.

Lewis, Daniel C. 2013. Direct Democracy and Minority Rights: A Critical Assessment of the Tyranny of the Majority in the American States. New York: Routledge. 
Montalvo, Jose G., and Marta Reynal-Querol. 2005. "Ethnic Polarization, Potential Conflict and Civil War." American Economic Review 95 (3): 796-816.

Posner, Daniel N. 2004. "Measuring Ethnic Fractionalization in Africa." American Journal of Political Science 48 (4): 849-863.

Smyth, David J., Pami Dua, and Susan Washburn Taylor. 1994. "Voters and Macroeconomics: Are They Forward Looking or Backward Looking?” Public Choice 78 (3-4): 283-293.

Verba, Sidney, and Norman H. Nie. 1987. Participation in America: Political Democracy and Social Equality. Chicago: University of Chicago Press.

White, Halbert. 1980. "A Heteroskedasticity-Consistent Covariance Matrix Estimator and a Direct test for Heteroskedasticity." Econometrica 48 (4): 817-838. 